\title{
Student Response Systems in Higher Education: Moving Beyond Linear Teaching and Surface Learning
}

\author{
Harry L. Dangel \\ Charles Xiaoxue Wang \\ Georgia State University
}

\begin{abstract}
Over the past decade, instructors in colleges and universities increasingly have used Student Response Systems (SRSS)--typically in large classes to increase the level of student engagement and learning. Research shows that both students and instructors perceive SRSs to be beneficial, although evidence of improved learning has been less clear. Experts emphasize that instructors must consider how technology might enhance good pedagogy in order for increases in learning to occur. SRSs do increase student engagement and provide prompt feedback-two key practices that promote learning. However, professional groups propose goals for students in higher education that focus on deep learning rather than the knowledge-centered emphasis of many large classes. Recent research shows that SRSs coupled with pedagogical enhancements can promote deep learning when teaching and questioning strategies center on higher-level thinking skills. A framework integrating the levels of student responses with principles for good pedagogical practice is provided as a guide for using SRSs to foster deep learning.
\end{abstract}

Key words: teaching methods, educational technology, student learning, student response systems, large classes

\section{Introduction}

The glass is half-full. We can foresee asking students to compose a "minute paper" describing the muddiest point for them in class that day (Angelo \& Cross, 1993) and then having them send their responses electronically for immediate compiling; or having students collaboratively develop a list of additional information they need before rendering a tentative diagnosis in a Problem-Based Learning class in nursing and then comparing those lists in real-time. These are instructional possibilities when using the emerging Student Response Systems (SRSs), often referred to as clickers. On the other hand, after encouraging colleagues to use clicker in their large lecture classes several years ago, we learned that there was not clear evidence that student learning had increased. While colleagues were convinced that students were more engaged and motivated and that attendance had improved, examination performances did not provide the hoped for evidence of increased learning. Our experience is not unusual, although such outcomes usually are not published.

This article presents a brief summary of SRS research, a framework for examining teaching and learning with SRSs in higher education and suggested directions for using this technology to improve student learning.

\subsection{What's in a name?}

We typically think of SRSs as the clicker systems used in the large lecture classes. When using SRSs instructors pose a question, 
problem, or statement, ask students to respond, and display the results. The systems have a variety of names: Audience Response System (e.g., Audience Response Systems in Higher Education, Banks, 2006), Classroom Response Systems (e.g., Classroom Response Systems: A Review of the Literature, Fies and Marshall, 2006), and Student Response Systems (e.g., Student response systems: A University of Wisconsin study of clickers, Kaleta \& Joosten, 2007). Consider what is implied by each name and how what we call the technology suggests how we would use it. An audience response system suggests that the action is in the front - on the stage. Students are more likely to be viewed as consumers who receive the instruction rather than being full partners in the instructional process. We wonder whether using the terms class or classroom implies a focus on group learning (teach to the middle) as opposed to individual students, as in student response system. A few authors (e.g., Guthrie \& Carlin, 2004) describe the technology as participation systems (a more collaborative approach) rather than response systems that suggest a pedagogical orientation of the instructor directing and student reacting. For this paper, we will use the term Student Response Systems because this term appears in the literature with increasing frequency and the emerging work clearly views students as more than an audience.

The pedagogical principles used with SRS originated with technologies as simple as the handheld slates or whiteboards on which children would write their answers to questions presented by the teacher. The teacher asks a question (e.g., "how do you write CAT?" or "How much are 2+2?"), and the students write their answers. A quick survey of the upheld slates/whiteboards enables the teacher to determine what portion of students responded correctly and adjust instruction accordingly. The modern equivalent of this simple technology is the erasable whiteboards used in some sciences courses (Crouch \& Mazur, 2001). What SRSs add is the ability to display the pooled results of the class. Today's SRSs are typically a clicker system, although there are more interactive systems being employed (e.g., using hand-held computers, PDAs, text messages from mobile phones).

\section{Beyond Surface Learning-What to Ask of Students?}

Recent reviews of the literature on the effects of using SRSs in higher education (Caldwell, 2007; Fies \& Marshall, 2006; Judson \& Sawada, 2002) provide a generally positive picture of the technology's impact on the classroom:

- Students and faculty consistently indicate that they have a positive view of SRSs, especially related to perceived improvement in attendance, engagement, and motivation (e.g., Hansen, 2007).

- SRSs are effectively used as preinstruction assessments (pretests or checks on homework or readings), surveys of knowledge or opinions, formative and low-stakes assessments, comprehension checks during lectures, assessments to launch or stimulate discussions, and quizzes and tests.

- SRSs have a positive or neutral impact on student learning.

- Research on the efficacy of SRSs to promote student learning typically lacks controls that are necessary to determine whether the technology or the accompanying pedagogical changes are responsible for apparent increases in learning.

- Evidence of a positive impact of SRSs is likely associated with the accompanying use of effective instructional practices (e.g., active learning). 
When we look more closely at the research findings, we question the impact of SRSs on learning. Initial use of SRSs dates back nearly fifty years as an effort to maximize student participation (Horowitz, 2006) and appeared to assume that with increased engagement, learning would follow. The title of recent articles, Waking the Dead (Guthrie \& Carlin, 2004), To Click or Not to Click (El-Rady, 2006), and Run a Class like a Game Show (Carnevale, 2005), emphasize the role that attendance and engagement have played for many faculty. Further, the multiple-choice format of the current commercial SRSs presents a challenge to faculty to move beyond asking questions about facts (recognizing a correct answer) presented in the lecture or text and to engage students in higher-level thinking.

We contrast these findings on SRSs with the high standards for learning that are being set for post-secondary students in the $21^{\text {st }}$ Century. The widely acclaimed white paper, Greater
Expectations (Association of American Colleges and Universities, 2002) proposes developing intentional learners who are grounded in a liberal education and empowered to:

- effectively communicate orally, visually, in writing, and in a second language,

- understand and employ quantitative and qualitative analysis to solve problems,

- interpret and evaluate information from a variety of sources,

- understand and work within complex systems and with diverse groups,

- demonstrate intellectual agility and the ability to manage change, and

- transform information into knowledge and knowledge into judgment and action.

A similar emphasis on broad, integrated skills related to literacy in technology is echoed in a recent article from the EDUCAUSE Center for Applied Research (Moore, Fowler, Jesiek, Moore, \& Watson, 2008). The proposed goals

Table 1. New Competencies for Learning (Moore, et al., 2008, p.5)

From (Current Prevalent Outlook)

Re-visioning movements are institutional focused, on inputs, changing courses, curricula, programs.

Coverage of domain material and skills is via individualistic, passive, and teacher-centered modes of instruction.

Students are approached and viewed as absolute knowers.

Students are encouraged to develop problemsolving abilities.

Teaching of skills that doe not lead to flexible skills of their application.

Skills and competencies are highly compartmentalized.

Students treated as passive receivers of information and unengaged learners.
To (New Learning Vision)

Re-visioning movements are studentfocused, on what students need to know and be able to do; competencies and outcomes are central.

Increasing emphasis on hands-on, mindson methods, authentic learning, and high concept/high touch capabilities

Students are approached and viewed as independent and contextual knowers.

Students are encouraged to develop problemsolving and problem-posing abilities.

Teaching of portable skills occurs

Information literacy, technology fluency, and domain knowledge are blended.

Students treated as big-picture thinkers and critically engaged doers. 
for students are shown in Table 1 below and are consistent with the shift from teacher-centered to learner-center instruction (Barr \& Tagg, 1995; Weimer, 2002).

We highlight a number of the words and phrases in the New Learning Vision column (right-side) that seem important and challenging when using SRSs. For example, authentic learning means that course goals and activities should be anchored in meaningful, real-life assignments and assessments-a special challenge for an instructor constructing multiple-choice questions. Likewise, problemposing abilities, and big-picture thinkers appear to challenge some of the ways that SRSs have been used.

The complexity of student learning goals described in the AAC\&U and EDUCAUSE reports requires rethinking traditional learning goals and classroom pedagogy. One of the tools available for faculty in designing goals for student learning along the lines suggested by these reports is Anderson and Krathwohl's (2001) revision of Bloom's Taxonomy of Educational Objectives. This seminal work redefines the original six components of cognitive learning objectives into active verbs that more accurately reflect what occurs in classrooms and a description of the activities that comprise deep learning (Biggs, 1996). The Cognitive Process Dimension consisting of:

Remembering: Retrieving, recognizing, and recalling relevant knowledge from long-term memory.

Understanding: Constructing meaning from oral, written, and graphic messages through interpreting, exemplifying, classifying, summarizing, inferring, comparing, and explaining.

Applying: Carrying out or using a procedure through executing or implementing.
Analyzing: Breaking material into constituent parts, determining how the parts relate to one another and to an overall structure or purpose through differentiating, organizing, and attributing.

Evaluating: Making judgments based on criteria and standards through checking and critiquing.

Creating: Putting elements together to form a coherent or functional whole; reorganizing elements into a new pattern or structure through generating, planning, or producing.

(Anderson \& Krathwohl, 2001, pp. 67-68).

It immediately becomes clear that the goals advocated by Moore, et al. (2008) are more aligned with cognitive skills beyond the "Remembering" level. The challenge for instructors is to facilitate students' ability to apply, analyze, evaluate, and create.

Instructors address the various levels of learning through the way we frame the questions we ask. For example, the stems for Remembering-level questions when using clickers is typically expressed as "Which is the...?" Such questions typically have a singledesired answer drawn from the lecture or readings and would fit in the left-hand column of Table 1's arrangement of competencies. Such applications are, unfortunately, least likely to produce the kind of transformational learning called for $21^{\text {st }}$ century students.

There are a number of recent examples of using SRS for Understanding, Applying, and Analyzing (Beatty, Leonard, Gerace, \& Dufresne, 2006; Beuckman, Rebello, \& Zollman 2006; Crossgrove, \& Curran, 2008). One stem for these items might be in the form of a survey ("What do you think is...?") that can provide the basis for discussions and exploring the elements of a concept. Also, multiple-choice 
questions can be developed to assess students' conceptual understanding. Here is an example of a conceptual understanding question in astronomy:

Given a picture of the waning quarter moon, what portion of the moon is illuminated by the sun? (a) $25 \%$; (b) $50 \%$; (c) 75 ; (d) $100 \%$; (e) none of those (Wilson, 2008)

In order to select the correct response to the question above, students must analyze the question to determine what is being asked, then select the relevant information and discard any information that is not relevant. In this case, "what portion of the moon is illuminated by the sun" is relevant and remembering the definition of waning moon and quarter moon are not relevant and need to be ignored. The sun always illuminates $50 \%$ of the moon regardless of what we can see from earth (except during lunar eclipses). Incorrect responses should be diagnostic to an instructor (e.g., if a student selects $25 \%$ as the answer, the instructor has some indication that the student was misled by the word quarter). Of course, designing and testing multiple-choice questions that tap into understanding, analyzing, and evaluating requires time and knowledge of both the content and of the types of errors and misconceptions of students.

The recent increase in the number of articles that address more complex learning using SRSs is encouraging. For example, after finding no significant differences in student performance in science classes on final examinations for classes using clickers and those that did not, Crossgrove and Curren (2008) implemented the use of clickers for high-level thinking questions. As a result their students did significantly better with multiple-choice questions that tested more content taught using clickers than on content taught without clickers. These differences held across the categories of remembering, comprehending, and applying/analyzing questions.

There is still limited evidence of SRSs applications in the Creating domain. Of course, students need an SRS technology that would afford them the tools to generate responses rather than just recognize response options. Beuckman, Rebello, and Zollman (2006) describe how their students used handheld computers to create answers. Their students had higher grades in physics courses when using handheld computers to construct responses compared to using a clicker system to select responses. PDAs, laptop computers, and even mobile phones offer the tools for producing individually-created responses given a system that can capture and display responses.

An especially interesting use of questions and SRSs to foster higher levels of learning is described by Beatty, Gerace, Leonard, and Dufresne (2006) in their research on effective questioning when teaching physics. Their model of using Question-Driven Instruction incorporates students'questions as the primary activity (rather than instructors' lecturing). This approach fundamentally changes the nature of teaching so that what the instructor says/does is guided by the students' questions and responses. The authors describe this approach as agile teaching because instructors are led by students' questions rather than instructors' questions leading students. When the instructors do ask questions, they include questions that assess conceptual knowledge, procedural knowledge, and metacognitive knowledge.

An instructor's guide to the effective use of personal response systems ("clickers") in teaching (CU Science Education Initiative \& UBC Carl Wieman Science Education 
Initiative, 2008) provides the following guidance:

By far the most common failing is to make questions that are too easy. In this situation, students often see the questions as simply a quiz to keep them awake, and they are annoyed that they had to spend money on clickers only for this purpose. There is also some indication that, in the absence of any other form of feedback, easy questions may mislead students as to the difficulty of the questions they would expect to see on the exam. In extensive surveys of students in many different classes, students overwhelmingly see challenging questions as the most useful for their learning. Our observations have also supported the conclusions that such questions result in greater learning (p. 7).

\section{Beyond Linear Teaching-How Do We Promote the Learning We Desire?}

In addition to redefining the learning outcomes to emphasize deep learning, we must consider how to redefine the pedagogy that guides our teaching. Consider this set of teaching tips for using a SRS (Robertson, 2000) that focus exclusively on presentation techniques almost ignoring elements related to promoting deep learning: keep questions short to optimize legibility, have no more than five answer options, do not make your questions overly complex, keep voting straightforward, allow time for discussion when designing your presentation, rehearse your presentation to ensure that it will run smoothly, provide clear instruction to your audience, and so on. Horowitz (2006) suggests a similar list.

Such guidance may be helpful but comes from a teacher-centered orientation and does little to address pedagogical issues, and just introducing new technologies does not address the pedagogical issues of how to improve student learning (Caldwell, 2007). As noted by Moore, et al. (2008), “... change starts with an examination of pedagogy and domain content if new learning is the aim. Only then can useful technologies and teaching strategies be matched to best achieve desired learning outcomes" (p. 3).

For the past two decades the Seven Principles for Good Practice in Undergraduate Education (Chickering \& Gamson, 1987) has been a cornerstone of pedagogical renewal. The principles, with more than fifty years of evidence supporting their effectiveness (Sorcinelli, 1991), are the product of a group of scholars in higher education who incorporated a series of reports and research on student learning into a comprehensive set of principles. The principles have been expanded and applied to numerous classroom settings in the years since they were originally published (Hatfield, 1995; Fink, 2003; Richlin 2006).

In Table 2 below, the list of the seven principles for good practice (Chickering and Gamson, 1987) are listed in the left-hand column. The principles have been reordered into what we judged to be more frequently employed with SRSs (e.g., time on task being allocating sufficient time for learning) through those more qualitative principles which have less frequently been integrated with using SRSs (e.g., communicating high expectations and respecting diverse talents and ways of knowing). It is interesting to analyze commonly used technology tools through the lens of the seven principles for good practice. For example, an instructor who is presenting information using PowerPoint often fails to address any of the seven principles. On the other hand, an instructor who has students work in teams to develop PowerPoint presentations is likely addressing several principles.

The Cognitive Process Dimension proposed by Anderson and Krathwohl (2001) is listed across the top with selected examples of the type of task that they suggest for each category. 
The cells in Table 2 have been shaded with the darkest cells representing the most commonly described applications of SRS--such as using the multiple-choice recall questions from the database that comes with the textbook. This use of a SRS promotes the Remembering domain and typically employs Time-on-Task and Frequent Feedback. Of course, it is critical thinking and deep learning (i.e., Understand, Analyze, and Evaluate levels) that represent the recommended goals for students (Association of American Colleges and Universities, 2004; Moore, et al, 2008) and the great challenge for instructors.
Much of the current literature about SRSs centers around two of the principles for good practice, (i.e., giving prompt feedback and emphasizing time on task). For example, improved student attendance, improve student motivation, and improved student engagement (Horowitz, 2006; Kaleta \& Joosten, 2007) are the most frequently cited benefits. To a larger extent, these benefits are quantitative changesrelated to attending and responding as opposed to being passive or even absent. While this is a positive outcome, the impact of using SRS on deep learning is more elusive.

Table 2. Principles for good practice (Chickering and Gamson, 1987)

\begin{tabular}{|c|c|c|c|c|c|c|}
\hline & \multicolumn{6}{|c|}{ Cognitive Learning Outcomes (Anderson \& Krathwohl, 2001) } \\
\hline & $\begin{array}{l}\text { Remember } \\
\text { recognize, } \\
\text { recall }\end{array}$ & $\begin{array}{l}\text { Understand } \\
\text { interpret, } \\
\text { classify } \\
\text { summarize, } \\
\text { compare }\end{array}$ & $\begin{array}{l}\text { Apply } \\
\text { execute, } \\
\text { implement }\end{array}$ & \begin{tabular}{|l|} 
Analyze \\
differentiate, \\
organize, \\
attribute
\end{tabular} & $\begin{array}{l}\text { Evaluate } \\
\text { check, } \\
\text { critique }\end{array}$ & $\begin{array}{l}\text { Create } \\
\text { plan, } \\
\text { produce }\end{array}$ \\
\hline $\begin{array}{l}\text { Emphasizes } \\
\text { Time-on-Task }\end{array}$ & \multirow{3}{*}{$\begin{array}{l}\text { Most } \\
\text { common } \\
\text { applications } \\
\text { of SRSs }\end{array}$} & \multirow{6}{*}{\multicolumn{4}{|c|}{$\begin{array}{l}\text { Emerging uses of SRSs, primarily in select } \\
\text { science programs-significant potential for } \\
\text { increased application. }\end{array}$}} & \multirow{7}{*}{$\begin{array}{l}\text { Areas for } \\
\text { potential } \\
\text { expansion } \\
\text { with } \\
\text { technologies } \\
\text { which } \\
\text { enable } \\
\text { students to } \\
\text { generate } \\
\text { responses } \\
\text { with SRSs }\end{array}$} \\
\hline $\begin{array}{l}\text { Gives Prompt } \\
\text { Feedback }\end{array}$ & & & & & & \\
\hline $\begin{array}{l}\text { Encourages } \\
\text { Faculty-Student } \\
\text { Contact }\end{array}$ & & & & & & \\
\hline $\begin{array}{l}\text { Develops } \\
\text { Student } \\
\text { Cooperation }\end{array}$ & \multirow{3}{*}{$\begin{array}{l}\text { Some use } \\
\text { is evident } \\
\text { in the } \\
\text { literature }\end{array}$} & & & & & \\
\hline $\begin{array}{l}\text { Encourages } \\
\text { Active Learning }\end{array}$ & & & & & & \\
\hline $\begin{array}{l}\text { Communicates } \\
\text { High } \\
\text { Expectations }\end{array}$ & & & & & & \\
\hline $\begin{array}{l}\text { Respects } \\
\text { Diverse } \\
\text { Talents/ } \\
\text { Knowing }\end{array}$ & \multicolumn{5}{|c|}{ Potential uses of SRSs remain largely untapped } & \\
\hline
\end{tabular}


The reordered Seven Principles follow with a brief description of how SRSs have been employed in higher education classrooms.

- Emphasizing time on task. "Allocating realistic amounts of time means effective learning for students and effective teaching for faculty" (Chickering \& Gamson, 1987, p.3). SRS enable faculty to increase attendance and student participation (e.g., time on task. In addition, if SRS can increase interest and engagement with the course content, students may increase time on task beyond the scheduled course time. On the other hand, taking time in class time for using SRS typically reduces coverage of content (Caldwell, 2007). The end result can be more learning for less teaching.

- Giving prompt feedback. Here is the heart of what SRS provides - prompt feedback to students' responses. But again, prompt feedback needs to provide the appropriate elements in order to be effective. While feedback using SRSs is appropriately prompt, feedback should also be directive and specific (Benson, Mattson, \& Adler, 1995). That is to say, feedback needs to contain the guidance students need in order to independently restructure correct responses in the future. This frequently means coupling Just-in-Time Teaching (JiTT) with SRS feedback in order to insure students understand the concepts being taught (Caldwell, 2007).

- Encouraging student-faculty contact. While this principle is a core practice, its application with technology is typically cited as contacts that occur beyond the classroom setting. As such, communication technologies are reported as the most effective ways encourage increased contact (Chickering \& Ehrmann, 1996).

- Encouraging cooperation among students. Using SRS has clear, positive impact on students' learning of complex material when paired with student cooperation. Mazur's (1997) work in physics on the impact of peer instruction provides a model for combining effective pedagogy and SRS to increase student learning (Beatty, Gerace, Leonard, and Dufresne, 2006).

- Encouraging active learning. Judson and Sawada (2002) conclude that when learning gains are seen, SRSs have been used to promote active learning. But, for active learning to be effective, it must be more then just clicking on a multiplechoice answer. Chickering and Ehrmann (1996) emphasize that to implement active learning with technology, students "must talk about what they are learning, write reflectively about it, relate it to past experiences, and apply it to their daily lives" (p. 4). With regard to SRSs, just using a clicker is not sufficient to engage students in the principles of active learning.

- Communicating high expectations. Although communicating high expectations is not intrinsically woven into SRS, the use of complex questions that require critical thinking can provide the opportunity to model deep learning within ones discipline (CU Science Education Initiative \& UBC Carl Wieman SEI, 2008).

- Respecting diverse talents and ways of learning. This principle offers a significant opportunity for faculty to capture voices from the back of the class (e.g., students who do not contribute to whole class discussions and who wait to judge the prevailing class sentiment before offering an opinion). Although SRSs using the format of multiplechoice responses do not capture all the diverse ideas present, a thoughtful 
instructor can, over time, integrate acceptable alternative explanations into the response options. Also, an instructor who uses the SRS to survey students or as a formative assessment should benefit from the additional information provided by the technology. For example, an instructor can instantly display the variety of views held by a class on an issue to be discussed in class and respectfully acknowledge the validity to that diversity. Thus far, there has been little research on how the use of SRSs impacts learning through this principle.

Beatty, et al. (2006) provide an excellent model for how Table 2 in action. Instructors' questions which reflect effective pedagogical principles (Chickering \& Gamson, 1987) can develop higher levels of learning (Anderson \& Krathwohl, 2001). These authors suggest posing the following array of questions and having students respond with a SRS:

- Survey students' background knowledge and attitudes related to concepts in the lesson.

- Display response patterns and discuss evidence of perceptions and prior knowledge.

- Explore areas of disagreement and confusion.

- Identify relationships between similarities and differences in the concepts.

- Based on evidence of understanding, elaborate on applying, analyzing, and evaluating the concept.

- Examine how understanding of the concept relates to other contexts and concepts.

Teaching in this manner places student understanding at the core of classroom activities and, as such, a SRS become essential to agile teaching and deep learning.

\section{SPSs as a System for Faculty Development}

Although most of the literature appropriately describes the impact of SRSs on student learning, several authors hint at the potential of the technology as a tool for faculty learning (Banks, 2006). For example, while feedback to students is a critical step in learning, the feedback that an instructor receives about student misconceptions and error patterns in reasoning provide a potentially rich source of information about how one might need to restructure readings, lectures, and course activities to address student difficulties. Without the frequent interactions and systematic display of students' responses, many of the patterns of students' misinterpretation, lack of prior knowledge, or incomplete logic would go unnoticed. Beatty et. al. (2006) note that effective questions can identify students' beliefs and prior knowledge about a topic and instantly communicate and store these results.

Data from SRSs also might be used to facilitate the Scholarship of Teaching and Learning (SoTL). One of the primary obstacles to instructors publishing SoTL research is their perception that capturing evidence of student learning is difficult and time consuming (Dangel, 2004). The ability of SRSs to collect and store evidence of students' understanding and their changes over time provides an effective tool for researchers to document student learning. Examples of how SRSs can be used as a tool to capture evidence of student learning in order to evaluate pedagogical approaches are beginning to emerge (Kennedy, Cutts, \& Draper, 2006)

\section{Guidance and Challenges in Using SRSs}

Probably the biggest challenge for effectively implementing SRSs is the time and effort needed to restructure courses and develop suitable, complex questions. With current commercial systems, this means developing multiple-choice 
questions with an appropriate array of choices. Ideally, many of the multiple-choice questions address deep learning and include response options that provide diagnostic information about students' thinking and reasoning (e.g., lack of prior knowledge, incomplete reasoning or faulty conclusions).

The research on SRSs has produced specific pedagogical recommendations which are in line with the educational goals noted above. First, instructors should ask questions that are appropriately challenging and require thinking skills beyond just remembering information. Second, students' questions or even students' responses to instructors questions can effectively serve as the roadmap for teaching. As Shulman (1999) notes, unless we take seriously what a student already knows, teaching becomes very difficult. Students' questions and, in many cases, their incorrect responses, can provide this information. Using SRSs to survey students' opinions and collect information about what students know requires instructors to adjust the way they engage students. Agile teaching (Beatty, et al., 2006) and just-in-time-teaching (Caldwell, 2007) replace the preset PowerPoint presentation and lecture in the paradigm shift from teaching to learning.

Faculty often notice that using SRSs results in covering less material (Caldwell, 2007). Yet, the potential of deeper learning as a result of reduced coverage is in line with pedagogical guidelines which call for emphasizing Big Ideas rather than coverage (Moore, et al. 2008; Wiggins \& McTighe, 2005). Covering less while teaching more effectively is certainly acceptable when there is clear evidence that learning has increased. Or, as Gardner emphasizes, "The greatest enemy of understanding is coverage" (Gardner 1993, p. 24).
Cost of the technology for students to use a SRS, whether clickers, PDAs, or hand-held computers, usually is borne by students. As such, they must be convinced that the cost is worth the benefit. Some textbook companies provide clickers at a reduced cost when faculty adopt their textbooks. Also, if a clicker is used in multiple classes, students will more likely accept the additional cost. And, as with any technology, increased support is needed because technical glitches are to be expected. Some students will forget to bring their clickers to class or lose them resulting in lost time and possible frustration (Lowery, 2005).

SRS technology offers great promise for engaging students and promoting learning, but only if we use this tool using sound pedagogical principles to promote learning that will be meaningful to students in the future. Although the glass is only half-full, it is still being filled as researchers share new classroom applications for this emerging tool that are based on sound pedagogical practices.

\section{References}

Anderson, L. W., \& Krathwohl, D. R. (Eds.). (2001). A taxonomy for learning, teaching and assessing: A revision of Bloom's Taxonomy of educational objectives: Complete edition, New York: Longman.

Angelo, T., \& Cross, P. (1993). Classroom assessment techniques: A handbook for college teachers ( $2^{\text {nd }}$ edition). San Francisco: Jossey-Bass.

Association of American Colleges and Universities. (2002). Greater expectations: A new vision for learning as a nation goes to college. Retrieved June 29, 2008 from http://www.aacu.org/gex/index.cfm

Barr, R. B., \& Tagg, J. (1995). From teaching to learning: A new paradigm for undergraduate education. Change, 27(6), 12-26.

Banks, D. A. (2006). Audience response 
systems in higher education: Applications and cases. Hershey, PA: Information Science.

Biggs, J. (1996). Enhancing teaching through constructive alignment. Higher education, 32, 347-364.

Beatty, I. D., Leonard, W. J., Gerace, W. J., \& Dufresne, R. J. (2006), Designing effective questions for classroom response system teaching. American Journal of Physics, 74(1), 31-39.

Benson, Mattson, \& Adler, 1995 in Hatfield, S. R. (1995). The seven principles in action: improving undergraduate education. Bolton, MA: Anker Publishing Co.

Beuckman, J., Rebello, N. S, \& Zollman, D. (2006). Impact of a classroom interaction system on student learning. AIP Conference Proceedings, 883:1, 129(4). Retrieved June 13, 2008 from http://web.phys.ksu.edu/ papers/2006/Beuckman_PERC2006.pdf

Caldwell, J. E. (2007). Clickers in large classrooms: Current research and bestpractice tips. CBE-Life sciences education, 6, 9-20.

Carnevale, D. (2005). Run a class like a game show: 'Clickers' keep students involved. Chronicle of Higher Education, 51(42), p.B3-B3.

Chickering, A. W., \& Ehrmann, S. E. (1996). Implementing the 7 principles: Technology as lever. American Association for Higher Education Bulletin, October, 3-6.

Chickering, A. W., \& Gamson, Z. F. (1987). Seven principles for good practice in undergraduate education. The Wingspread Journal, 9(2), 1-16.

Crouch, C. H., \& Mazur, E. (2001). Peer instruction: Ten years of experience and results. American Journal of Physics, 69, 970-977.

Crossgrove, K., \& Curran, K. L. (2008). Using clickers in non-majors- and majors-level biology courses: Student opinion, learning, and long-term retention of course material.
CBE-Life sciences education, 7, 146-154.

CU Science Education Initiative \& UBC Carl Wieman Science Education Initiative. An instructor's guide to the effective use of personal response systems ("clickers") in teaching. Vancouver: University of British Columbia. Retrieved June 13, 2008 from http://www.cwsei.ubc.ca/resources/files/ Clickers_Final_Version_04_08.pdf

Dangel, H. (2004, November). A faculty learning community for the scholarship of teaching and learning. Professional Organization Development Network Conference. Montreal, Canada.

El-Rady, J. (2006). To click or not to click: That is the question. Innovate: Journal of online education, 2(4). Retrieved June 28, 2008 from http://www.innovateonline.info/ index.php?view $=$ article $\& \mathrm{id}=171$

Fink, L. D. (2003). Creating significant learning experiences: An integrated approach to designing college courses. San Francisco: Jossey-Bass.

Fies, C., \& Marshall, J. (2006). Classroom response systems: A review of the literature. Journal of Science Education and Technology, 15.

Gardner, H.W. (1993). 'Educating for understanding'. The American School Board Journal, July, 20-24.

Guthrie, R. W., \& Carlin, A. (2004). Waking the dead: Using interactive technology to engage passive listeners in the classroom. Proceedings of the Tenth Americas Conference on Information Systems, New York. Retrieved June 13, 2008 from http://www.mhhe.com/cps/docs/CPSWP WakindDead082003.pdf

Hansen, C. R. (2007). An evaluation of a student response system used at Brigham Young University. Masters Thesis. Retrieved June 13, 2008 from http://contentdm.lib.byu.edu/ ETD/image/etd2127.pdf

Hatfield, S. R. (1995). The seven principles in action: improving undergraduate 
education. Bolton, MA: Anker Publishing Co.

Horowitz, H. M. (2006). ARS revolution: Reflections and recommendations. In D. A. Banks (Ed.), Audience response systems in higher education: Applications and cases (pp. 53-63). Hersey, PA: Information Science.

Judson, E., \& Sawada, D. (2002). Learning from past and present: Electronic response systems in college lecture halls. Journal of Computers in Mathematics and Science Teaching 21(2), 167-181.

Kaleta, R, \& Joosten, T. (2007) Student response systems: A University of Wisconsin study of clickers. (Research Bulletin, Issue 6). Boulder, CO: EDUCAUSE Centerfor Applied Research. Retrieved June 13, 2008 from http:// connect.educause.edu/Library/ECAR/St udentResponseSystemsAUn/40166

Kennedy, G. E., Cutts, Q., \& Draper, S. W. (2006). In D. A. Banks (Ed.), Evaluating electronic voting systems in lectures: Two innovative methods (pp. 155-174). Hersey, PA: Information Science.

Lowery, R. C. (2005). Teaching and Learning with Interactive Student Response Systems: A Comparison of Commercial Products in the Higher-Education Market. Annual meeting of the Southwestern Social Science Association. New Orleans. Retrieved June 20, 2008 from http://people.uncw.edu/ lowery/SWSSA\%20ms.pdf

Mazur, E. (1997). Peer instruction: A user's manual, Upper Saddle River, NJ: Prentice Hall.

Moore, A. H., Fowler, S. B., Jesiek, B. K., Moore, J. F., \& Watson, C. E. (2008). Learners 2.0? IT and 21stCentury Learners in Higher Education. (Research Bulletin, Issue 7). Boulder, CO: EDUCAUSE Center for Applied Research, 2008. Retrieved June 13, 2008 from http://connect.educause.edu/
Library/ECAR/Learners20ITand21stCen tur/46519

Richlin, L. (2006). Blueprint for learning: Constructing college courses to facilitate, assess, and document learning. Sterling, VA: Stylus.

Robertson, L. J. (2000). Twelve tips for using a computerized interactive audience response system. Medical Teacher, 22(3), 237-240.

Sorcinelli, M. D. (1991). Research findings on the seven principles. In A.W. Chickering and Z. F. Gamson (eds). Applying the seven principles of good practice in undergraduate education (pp.13-25). San Francisco: Jossey-Bass.

Shulman, L. S. (1999). Taking learning seriously. Change, 13(4), 11-17.

Weimer, M. (2002). Learner-centered teaching: Five key changes to practice. San Francisco: Jossey-Bass.

Wiggins, G. P., \& McTighe, J. (2005) Understanding by design ( $2^{\text {nd }}$ ed.). Alexandria, VA: Association for Supervision and Curriculum Development.

Wilson, J. (2008). Using clickers in a large astronomy class. PRISM spring workshop. Georgia State University.

\section{Contact the Authors}

Harry L. Dangel, Ph.D.

Georgia State University

Email: hdangel@gsu.edu

Charles Xiaoxue Wang, Ph.D.

Georgia State University

Email: xwang10@gsu.edu 